\title{
Designing a Virtual World to Mirror the Real Challenges of Life as an Amputee
}

\author{
Sandra L Winkler ${ }^{1}$, John Kairalla ${ }^{2}$, Ann Ludwig ${ }^{3}$, Chris Fowler ${ }^{4}$ \\ 1,4 James A HaleyVA Hospital, sandra.winkler@va.gov, christopher.fowler3@va.gov \\ ${ }^{1}$ Nova Southeastern University \\ ${ }^{2}$ University of Florida,jak@biostat.ufl.edu \\ ${ }^{3}$ Virtual Ability, Inc, emecapalini@gmail.com
}

\begin{abstract}
The purpose of this research was to further understand the experience of using a customized avatar in a virtual world to practice desired health behaviors. By triangulating the quantitative and qualitative data of 12 amputee participants, we discovered that salient factors of having an amputation had a profound impact on the measure of health outcomes. This in turn masked the measured effect of the virtual self-management intervention on health outcomes. We also learned that our training was not closely enough aligned with the constructs that we measured. We discuss how to address these gaps in future studies including adding serious games to a virtual world environment to facilitate disclosure of and adjustment to the salient factors and to better align the simulations with desired outcomes.
\end{abstract}

Keywords: Amputee, Amputation, Self-management, Virtual, Virtual world, Simulation

\section{Introduction}

Virtual worlds have the capacity to mutually penetrate the digital and physical worlds, providing an ideal environment for enabling [1] self- management for individuals with limb loss and amputation for whom acquiring current and evolving prosthetic and health-related information is an ongoing process. This project developed a virtual self-management training for amputees where amputees viewed themselves as avatars performing desired health behaviors. Our virtual world environment, Virtual Health Adventures, built in Second Life ${ }^{\circledR}$ (SL), provided opportunities for leisure and socialization, such as a prosthetic museum (Figure 1a), an amphitheater for formal continuing education (Figure 1a), and recreational activities like windsurfing and hang gliding (Figure 1c).

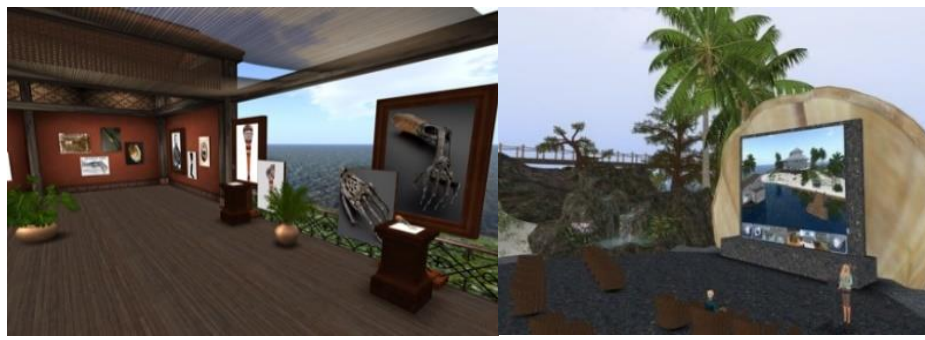

Figure 1a. Prosthetic Museum 1b. Amphitheater

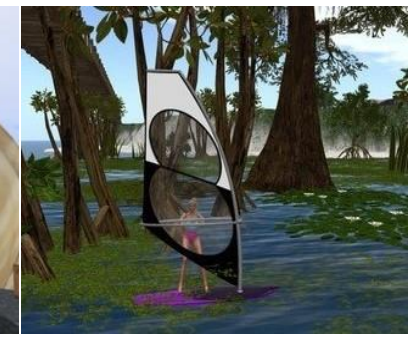

1c. Leisure

A 17-station intervention (Figure 2a) was partitioned into an invisible grid of 17 parcels that allowed multiple videos to be played simultaneously, without voice at one station interrupting voice at other stations. As avatars walked onto the station platform, the screen instructed them to be seated then click on the forward arrow to begin the simulation (Figure 
$2 \mathrm{~b})$. The balance training simulation shown in Figure $2 \mathrm{c}$ is activated when the participant follows the instruction to click on the blue cane, which adds the cane to the participant's inventory. The participant then goes to their inventory and wears the blue cane which animates their avatar to perform the same activity as the actor in the video. The simulations were created using Blender software. All simulations were modeled, textured, and animated by hand, working closely with provided reference information. The animations were then exported using a format designed specifically for SL.

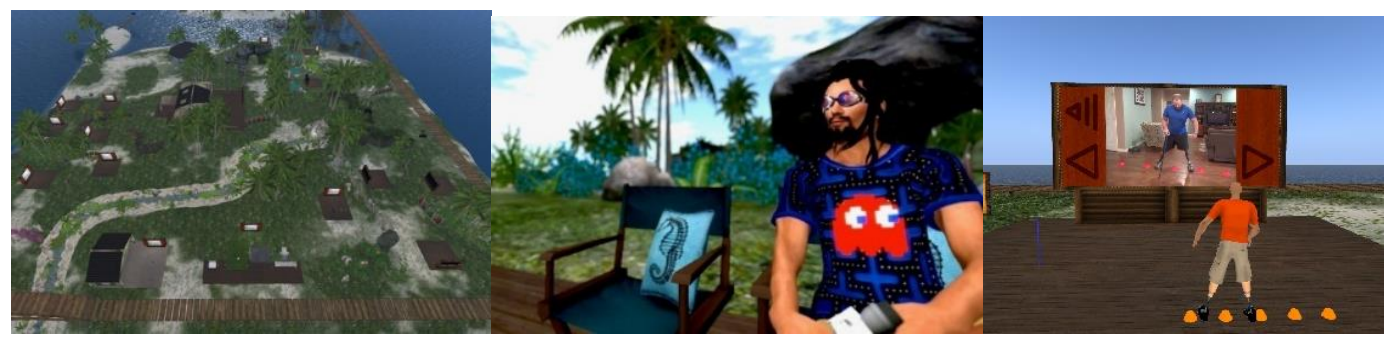

Figure 2a. Arial view of stations 2b. Initiating lesson 2c. Avatar practicing behavior

The analysis described in this manuscript was a part of a larger randomized study [2-4] that compared the dissemination of a self-management intervention via e-learning and virtual world. The scientific goal of the research described in this manuscript was to further understand the experience of using a customized avatar in a virtual world by triangulating previously published quantitative [2] and qualitative [4] (experience of the virtual world) data. The research question was: to what extent can triangulating quantitative [2] and qualitative [4] data further explain the observed small effect sizes (quantitative data) yet unanimous positive experiece with the virtual world environment (qualitative data)? The problem mitigated by our mixed-methods approach was the disparity between our initial quantitative and qualitative findings, i.e., if users unanimously found the virtual world effective, why was this effect not reflected in the outcomes?

\section{Methods}

This study was approved by the Nova Southeastern University Institutional Review Board. The participants included all 12 amputees who were randomized to and completed the selfmanagement training in the virtual world and the semi-structured interview in a previous larger study. This manuscript reports the results of mixing, or triangulating, the previously collected quantitative [2] and qualitative [4] data to further explore and explain the small effect sizes yet unanimously positive qualitative data.

From prior publication [2], virtual world outcomes with pre to post intervention effect sizes (ES; difference divided by standard deviation of change) included pain

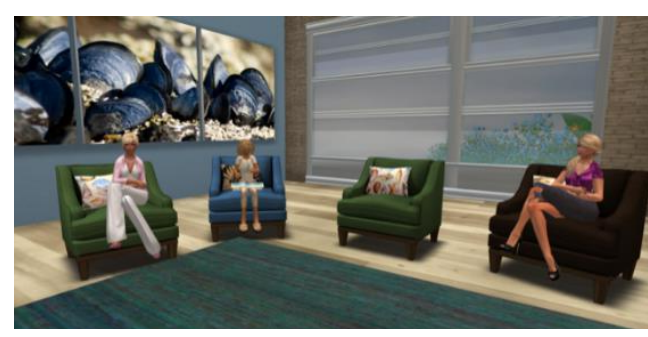

Figure 3. Virtual interview room interference $(E S=-0.21)$, perceived social support $(E S=0.30)$, general self efficacy $(E S)=0.11$, and lower limb function $(E S=0.37)$. Previously described qualitative data (Figure 3) included a semi-structured interview item: "Describe your experience in SL", with prompts such as "What was it like to go through the training with your avatar?" etc. Qualitative data were reanalyzed for the mixed analysis with a focus on experience of the virtual world. Transcripts were initially coded line-by-line [5, 6]. Table 1 shows a segment of the interview text and associated line-by-lines codes. Next, the initial codes were categorized into themes. Magnitude coding [6] was then performed to quantify the 
qualitative data to mix with quantitative outcomes data. Magnitude coding applies a number to the data to indicate the direction of the response. For this analysis, magnitude codes were operationally defined as follows: $1=$ negative perception, $2=$ mixed positive and negative perceptions, or $3=$ positive perception. For each participant, each theme was assigned a magnitude code then mixed, or triangulated, with the quantitative outcomes data [2] for pain interference, social support, self-efficacy, and function outcomes.

Table 1. Process of initial coding of interview text.

\begin{tabular}{|l|l|}
\hline Interview Text & Initial Codes \\
\hline I: How did it feel doing training as an Avatar? & $\begin{array}{l}\text { Strange at first } \\
\text { enjoyed as i went along } \\
\text { S10: kind of strange at first but i enjoyed it as i went along }\end{array}$ \\
$\begin{array}{l}\text { I: What made you feel that way? } \\
\text { S10: it was hard looking at myself as a avatar } \\
\text { hard looking at myself as } \\
\text { avatar }\end{array}$ \\
$\begin{array}{l}\text { I: Overall, how did you feel about this training experience? } \\
\text { S10: i really enjoyed it the education alone was worth it } \\
\text { I: What specifically really resonated with you? }\end{array}$ \\
$\begin{array}{l}\text { S10: the ability to connect with other amputees } \\
\text { S54: Well, I'm not sure. I think going into it I had expectations of it } \\
\text { being very different from just doing some reading, but to me it } \\
\text { seemed as though I just walked from station to station and then read } \\
\text { from the slides }\end{array}$ \\
$\begin{array}{l}\text { I: What were your specific expectations? } \\
\text { S54: Well I didnt really know what I was getting into really. I may } \\
\text { have been envisioning something more like a virtual reality } \\
\text { simulator. }\end{array}$ \\
$\begin{array}{l}\text { amputees } \\
\text { expectations different } \\
\text { w: Oh I see... What was it about thion to station } \\
\text { read slides }\end{array}$ \\
$\begin{array}{l}\text { with you? } \\
\text { S54: I think seeing my person go through some of the exersises } \\
\text { helps to see how things can be done }\end{array}$ & envisioning VR \\
\hline S=Subject, I=Interviewer & \\
\hline
\end{tabular}

\section{Results}

\subsection{Coding}

Two themes emerged from the initial coding (Table 2): (1) avatar human-computer interface and (2) self-management training content. Tables 3 and 4 show the magnitude coding process and results for all 12 participants. Most participants agreed with the sentiment that the virtual world was "confusing at first. When you first log in you have a lot to take in. ... However, once the newness of the world becomes familiar then ... it is easier to navigate." 
Table 2. Organizing initial codes into themes.

\begin{tabular}{|c|c|c|c|}
\hline ID & Initial Codes & $\begin{array}{c}\text { Human-Computer } \\
\text { Interface }\end{array}$ & Training Content \\
\hline S10 & $\begin{array}{l}\text { amazing } \\
\text { good to see my leg again } \\
\text { liked hx of prostetics } \\
\text { strange at first } \\
\text { enjoyed as I went along } \\
\text { education worth it } \\
\text { connect with other amputees }\end{array}$ & $\begin{array}{l}\text { amazing } \\
\text { good to see my leg again } \\
\text { strange at first } \\
\text { enjoyed as I went along }\end{array}$ & $\begin{array}{l}\text { liked hx of } \\
\text { prosthetics } \\
\text { education worth it } \\
\text { connect with other } \\
\text { amputees }\end{array}$ \\
\hline S54 & $\begin{array}{l}\text { expectations different } \\
\text { walked station to station } \\
\text { read slides } \\
\text { envisioning VR } \\
\text { seeing exercises helps } \\
\text { see how things can be done }\end{array}$ & $\begin{array}{l}\text { expectations different } \\
\text { walked station to station } \\
\text { read slides }\end{array}$ & $\begin{array}{l}\text { seeing exercises } \\
\text { helps } \\
\text { see how things can be } \\
\text { done }\end{array}$ \\
\hline
\end{tabular}

Table 3. Segment of magnitude coding of initial codes per themes.

\begin{tabular}{|c|c|c|c|c|c|}
\hline ID & & & Initial Codes & $\begin{array}{c}\text { Human-Computer } \\
\text { Interface }\end{array}$ & Training Content \\
\hline S10 & 3 & 3 & $\begin{array}{l}\text { amazing } \\
\text { good to see my leg again } \\
\text { liked hx of prostetics } \\
\text { strange at first } \\
\text { enjoyed as I went along } \\
\text { education worth it } \\
\text { expectations different } \\
\text { walked station to station } \\
\text { read slides } \\
\text { envisioning VR } \\
\text { seeing exercises helps }\end{array}$ & $\begin{array}{l}\text { amazing } \\
\text { good to see my leg again } \\
\text { strange at first } \\
\text { enjoyed as I went along } \\
\text { expectations different } \\
\text { walked station to station } \\
\text { read slides }\end{array}$ & $\begin{array}{l}\text { education worth it } \\
\text { seeing exercises } \\
\text { helps }\end{array}$ \\
\hline
\end{tabular}

\subsection{Mixing}

Table 5 shows the mixing of the theme magnitude codes with the changes in outcomes values pre and post self-management training. The second and third columns show the magnitude value per the Human-Computer Interface (HCI) and Training Content (Cont) themes, per participant. The last four columns show whether the change in outcome improved (coded as a "1"), got worse (coded as a "0"), or did not change (no code) for each of the four outcome measures. Outcomes of participants were shaded according to whether, they improved or remained unchanged on all four outcomes (lightest shading, $\mathrm{N}=6$ ), worsened or stayed the same (darkest shading, $\mathrm{N}=5$ ), and participants who improved on some outcomes but worsened on others (mid-range shading, $\mathrm{N}=1$ ). The pattern (Table 5) indicates only a chance relationship between a perception of the virtual world and a change in outcomes. 
Table 4. Magnitude coding

\begin{tabular}{|l|cc|}
\hline ID & $\begin{array}{c}\text { Human- } \\
\text { Computer } \\
\text { Interface }\end{array}$ & $\begin{array}{c}\text { Training } \\
\text { Content }\end{array}$ \\
\hline S54 & 2 & 3 \\
S3 & 3 & 3 \\
S10 & 3 & 3 \\
S14 & 3 & 3 \\
S28 & 3 & 3 \\
S29 & 3 & 3 \\
S37 & 3 & 3 \\
S38 & 3 & 3 \\
S40 & 3 & 3 \\
S47 & 3 & 3 \\
S51 & 3 & 3 \\
S55 & 3 & 3 \\
\hline
\end{tabular}

Table 5. Mixing of magnitude and outcomes data. HCI=Human-Computer Interface, Cont=

Training Content, PI=Pain interference, $S S=$ Social support, $S S E=$ Self-efficacy, $F=$ Function

\begin{tabular}{|l|cccrrr|}
\hline ID & HCI & Cont & PI & SS & SSE & F \\
\hline S54 & 2 & 3 & & 1 & & 1 \\
S3 & 3 & 3 & & 1 & & 1 \\
S10 & 3 & 3 & 1 & 1 & 1 & \\
S40 & 3 & 3 & 1 & 1 & & 1 \\
S47 & 3 & 3 & & 1 & 1 & 1 \\
S55 & 3 & 3 & & 1 & 1 & 1 \\
S14 & 3 & 3 & 0 & 0 & 0 & 0 \\
S28 & 3 & 3 & & 0 & 0 & 0 \\
S29 & 3 & 3 & 0 & & & 0 \\
S37 & 3 & 3 & 0 & 0 & & \\
S51 & 3 & 3 & & 0 & & \\
S38 & 3 & 3 & 1 & 0 & 1 & \\
\hline
\end{tabular}

\section{Discussion}

The purpose the mixed-methods analysis described in this manuscript was to further understand previously published small effect sizes (quantitative data) [2] yet unanimously positive experience with the virtual world (qualitative data) [4]. These data were published as part of a larger randomized controlled study that compared the dissemination of a selfmanagement training under e-learning and virtual world conditions [2-4]. The larger study found that while amputees described the virtual world as a positive experience, there was only a trend (and small effect sizes) towards improved health outcomes. Mixing the quantitative [2] and qualitative data [4], failed to provide an explanation for this chance relationship, e.g., amputees who were more engaged in the virtual training did not necessarily demonstrate better outcomes. We offer two possible explanations, the outcomes measured and time engaged in and quality of training.

We discovered, via qualitative interviews, that other salient events in the participants' lives were affecting outcomes. For example, serious distraction included fear of falling and injury, fear of infection, the need to find employment, becoming homeless, grieving the death of a loved one in the accident that led to the amputation, and adverse events that occurred during a total knee replacement surgery that subsequently required amputation of the limb. This finding suggests that the constructs we measured were not adequately aligned with amputees' true life challenges. Our data collection could have been improved by asking questions such as: "Were there important or adverse events that occurred at the time of your trauma/amputation?" or "Tell me about any other important events that occurred during the study period." Second, our quantitative measures were not adequately sensitive to change. Without prompting, several participants commented on peer and social support and pain interference as positive virtual world experiences, yet the perceived social support and pain interference measures showed only small to medium effect sizes.

During the qualitative interviews, several amputee participants suggested using reward mechanisms, such as points or badges (gamification), to establish personalized goals and help them remain engaged with the training in order to turn the desired health behaviors into habits [7]. Another way to increase duration and intensity of engagement would be to develop and incorporate a serious game [7] that collected participant information about daily habits and health outcomes. As amputees progress through the stations, they could set 
pag. 110

goals and deadlines, and mark tasks as completed to earn rewards. Games could be developed that actively address amputee participants' anxiety and grieving challenges. A game could also help amputees through the evidence-based knowledge maze. For example, the game could feature a wizard that provides amputees with clues as to where they might find the information that they are looking for. Adding these serious games to the virtual training could keep the amputees engaged in the virtual world longer and thus extend the benefits.

This study had several limitations. First, it is likely that the participants who did not experience the virtual world positively dropped out of the study: the virtual world arm had only a $50 \%$ completion rate). Second, the sample size was small. Third, due to limited resources, follow-up qualitative interviews with participants were not performed.

\section{Conclusion}

Amputees positively perceived the experience of self-management training as an avatar in a virtual world although there was only a chance relationship between experience in the virtual world and change in health outcomes. Our findings suggest this chance relationship is likely a result of insufficient accordance between specific training simulations and the constructs measured, and the impact of unanticipated salient features of amputation on health outcomes. Adding serious games to virtual world training could increase duration and intensity of engagement, thus improving the formation of positive health habits .

\section{Acknowledgments}

This work was supported by the Agency for Healthcare Research and Quality, 1R24HS022021, 2013-2017.

This material is the result of work supported with resources and the use of facilities at the James A. Haley Veterans' Hospital. As Department of Veterans Affairs employees, the contents do not represent the views of the Department of Veterans Affairs or the United States Government.

\section{References}

[1] U. Lucke and R. Zender, "3D Interactions between Virtual Worlds and Real Life in an ELearning Community," Adv. Hum. Comput. Interact., Jan. 2011, Art. no. 6. doi: $10.1155 / 2011 / 684202$.

[2] S. L. Winkler, J. Kairalla, A. Hall, M. Schlesinger, A. Krueger, and A. Ludwig, "Comparison of functional benefits of self-management training for amputees under virtual world and elearning conditions," J. Alter. Med. Res., vol. 10, no. 1, pp. 65-72, June 2018.

[3] S. L. Winkler et al., "Self-management intervention for amputees in a virtual world environment," in Recent Advances on Using Virtual Reality Technology for Rehabilitation, P. Sharkey and J. Merrick, Eds., Hauppauge, NY, USA: Nova Science Publishers, 2016, ch. 4, pp. 25-32.

[4] R. Cooper et al., "Expanded sense of possibilities: Qualitative findings from a virtual selfmanagement training for amputees," J. Alter. Med. Res., vol. 10, no. 1, pp. 73-79, June 2018.

[5] K. Charmaz, Constructing grounded theory, 2nd ed. Los Angeles, CA, USA: Sage, 2014. ISBN: 9780857029140.

[6] J. Saldana, The coding manual for qualitative researchers. Thousand Oaks, CA, USA: Sage, 2013. doi:10.1177/0092055X18760362

[7] T. K. Barik, E. Murphy-Hill, and T. Zimmermann, "A Perspective on Blending Programming Environments and Games: Beyond Points, Badges, and Leaderboards," in 2016 IEEE Symp. Visual Languages and Human-Centric Computing (VL/HCC), Cambridge, UK, September 4-8 2016. doi: 10.1109/VLHCC.2016.7739676. 